\title{
A TERCEIRIZAÇÃO NA UFGD EM TEMPOS DE PANDEMIA DO SARS-COV-2
}

\author{
Recebido em 31/03/2021, aprovado em 13/05/ 2021 \\ 10.30612/mvt.v8i14.15020 \\ João Gustavo Jara Russo' \\ Vinicius Farias de Souza²
}

RESUMO: O presente artigo tem por objetivo abordar a terceirização na Universidade Federal da Grande Dourados (UFGD), especificamente em tempos de pandemia do Sars-CoV-2 (COVID-19) no intuito de dar visibilidade à questáo e aos trabalhadores terceirizados. Há um quadro de tendência global em que a terceirizaçáo no mundo do trabalho se apresenta como reflexo da implementação de políticas neoliberais, resultando em negação e perda de direitos laborais, fragmentação da classe trabalhadora, degradação do trabalho, desvalorização, desrespeito, invisibilidade e exclusão do trabalhador terceirizado. O referencial teórico metodológico utilizado será o da sociologia do trabalho, a partir de uma revisão bibliográfica com natureza exploratória, não objetivando esgotar a temática (considerando que o enfrentamento à pandemia não se findou), com enfoque na situação da terceirização anteriormente à pandemia, bem como através da técnica de pesquisa da análise documental de documentos públicos emitidos pela UFGD na atualidade pandêmica sobre a questáo. A princípio será apresentado um breve panorama da terceirização na Administração Pública brasileira, bem como a posição da UFGD neste cenário, utilizando dados coletados de uma pesquisa de mestrado realizada no Programa de Pós-Graduaçáo em Sociologia que analisou o processo de terceirização na instituição de ensino. Em um segundo momento, será abordada, através da análise de documentos públicos institucionais, os aspectos que implicam na conjuntura da terceirização na instituição durante a pandemia. Os resultados demonstram o reforço da questão da precarização do trabalho por diversos aspectos, dentre os quais a invisibilidade e exclusão do trabalhador terceirizado do quadro da comunidade acadêmica.

Palavras-chave: Terceirização. Precarização. Pandemia.

OUTSOURCING AT UFGD IN PANDEMIC TIMES OF SARS-COV-2

ABSTRACT: This article aims to address outsourcing at the Federal University of Grande Dourados (UFGD), specifically during the Sars-CoV-2 (COVID-19) pandemic, in order to turn visible the

\footnotetext{
1 Mestre pelo programa de Pós-graduação em Sociologia da Universidade Federal da Grande Dourados (UFGD) (2019). Especialista em Direito e Processo do Trabalho pelo Damásio Educacional (2016). Graduado em Direito pelo Centro Universitário da Grande Dourados (2013). Advogado (2014). Orcid: https://orcid.org/0000-0002-9005-6475. Email: (joao. gustavo_jr@hotmail.com).

2 Graduado em Direito pela Universidade Federal da Grande Dourados (2014). Especialista em Gestão Pública pela Universidade Federal da Grande Dourados (2016). Mestrando pelo programa de Pós-graduação em Sociologia da Universidade Federal da Grande Dourados (2020). E-mail: souza.viniciusf@gmail.com
} 
issue of outsourcing and outsourced workers. Theglobal tendency of labor outsourcing is a reflection of the implementation of neoliberal policies resulting in denial and loss of labor rights, fragmentation of the working class, degradation of work, devaluation, disrespect, invisibility and exclusion of outsourced workers. The theoretical and methodological framework is based on a bibliographic review of sociology of labor and exploratory investigation, focusing on the situation of outsourcing prior to the pandemic and a research technique of documentary analysis of public documents issued by UFGD in the current pandemic. It's worth mentioning that the article does not present a definitive overview of this issue, as the confrontation with the pandemic has not yet ended. At first, a brief overview of outsourcing in the Brazilian Public Administration will be presented, as well as UFGD's position in this scenario, based on data from a master's research carried out in the Postgraduate Program in Sociology that analyzed the outsourcing process in the educational institution. In a second moment, the aspects that imply the situation of outsourcing in the institution during the pandemic will be addressed, through the analysis of institutional public documents. Our results show the reinforcement of precarious work, due to several aspects, as invisibility and exclusion of the outsourced worker in the academic community.

KEYWORDS: Outsourcing. Precarious Work. Pandemic.

\section{TERCERIZACIÓN EN UFGD EN TIEMPOS DE PANDEMIA DE SARS-COV-2}

RESUMEN: Este artículo tiene como objetivo abordar la subcontratación en la Universidad Federal de Grande Dourados (UFGD), específicamente en tiempos de la pandemia Sars-CoV-2 (COVID-19), con el fin de dar visibilidad al tema de la subcontratación y a los trabajadores subcontratados, considerando un marco existente de tendencia global que la subcontratación en el mundo del trabajo es un reflejo de la implementación de políticas neoliberales, resultando en la negación y pérdida de los derechos laborales, fragmentación de la clase trabajadora, degradación del trabajo, devaluación, falta de respeto, invisibilidad y exclusión de trabajadores subcontratados. El marco teórico y metodológico utilizado será el de la sociología del trabajo, a partir de una revisión bibliográfica de carácter exploratorio, no con el objetivo de agotar el tema, considerando que el enfrentamiento con la pandemia no ha terminado, centrándose en la situación de la subcontratación previa a la pandemia, así como a través de la técnica de investigación de análisis documental de documentos públicos emitidos por la institución UFGD en la actual pandemia. En un primer momento, se presentará un breve panorama de la subcontratación en la Administración Pública Brasileña, así como la posición de la UFGD en este escenario, utilizando datos recopilados de una investigación de maestría realizada en el Programa de Posgrado en Sociología que analizó el proceso de subcontratación en el institución educativa. En un segundo paso, se abordarán, a través del análisis de documentos públicos institucionales, los aspectos que implican en la coyuntura de la subcontratación en la institución durante la pandemia, y el reforzamiento del tema de la precariedad del trabajo, por varios aspectos, entre ellos, la invisibilidad y exclusión del trabajador subcontratado en la comunidad académica.

Palavras Clave: Tercerización. Trabajo Precario. Pandemia.

\section{A REESTRUTURAÇÃO CAPITALISTA: NEOLIBERALISMO E A TERCEIRIZAÇẪO NA ADMINISTRAÇÃO PÚBLICA BRASILEIRA}

A configuração adotada pelo mundo do trabalho, nas últimas décadas, pós-crise do Fordismo, nos traz efeitos postos pelo neoliberalismo que, aqui, vamos tratar como um conjunto de ideias 
e políticas públicas, conforme expóe Filgueiras (2021), em uma reestruturaçáo produtiva e de flexibilização das relações de trabalho. Ricardo Antunes (2000, p. 35) nos ensina que esses efeitos de caráter destrutivo são "entre tantos aspectos nefastos, um monumental desemprego, uma enorme precarização do trabalho e uma degradação crescente, na relação metabólica entre homem e natureza". Neste, particular Antunes (2000, p. 35) ainda refere que a lógica que conduz essa marcha é "prioritariamente para a produção de mercadorias, que destrói o meio ambiente em escala globalizada" e, neste patamar, "entre tantas destruiçóes de forças produtivas, da natureza e do meio ambiente, há também, em escala mundial, uma ação destrutiva contra a força humana de trabalho, que encontra-se hoje na condição de precarizada ou excluida" (ANTUNES, 2000, p. 37-38).

Vale lembrar que o contexto referido do capitalismo contemporâneo é de uma crise estrutural, com sua lógica destrutiva cada vez mais evidente. Antunes (2000) resume as tendências que surgem neste contexto de crise estrutural do capital, a saber: a substituição do padrão produtivo taylorista e fordista por formas produtivas flexibilizadas e desregulamentadas; o modelo de Estado de bem estar social presente nos países centrais que vem sendo derrubado pela desregulação neoliberal, privatizante e anti-social. O autor nos expóe, ainda, que esse ideário neoliberal foi primeiramente implementado pelos países centrais e, logo após, os países subordinados foram contemplados, em específico com a agenda de reestruturação produtiva, privatização acelerada, enxugamento estatal, políticas fiscais e monetárias em sintonia com órgãos mundiais de hegemonia do capital, como o Fundo Monetário Internacional (FMI): “com a enorme expansão do neoliberalismo a partir de fins de 70 e a consequente crise do welfare state, deu-se um processo de regressão da própria socialdemocracia, que passou a atuar de maneira muito próxima da agenda neoliberal" (ANTUNES, 2000 , p. 40). A viabilização da terceirização como forma de contratação no Brasil foi estabelecida neste panorama, segundo Krein (2007), no contexto de uma crise econômica, abertura comercial e financeira com a valorização cambial, redefinição do papel do Estado, reestruturação e opção política pelo neoliberalismo.

O Brasil, no início da década de 1990, passava por diversas incertezas político-econômicas como a recente redemocratização do país após um conturbado período de Ditadura EmpresarialMilitar, com cenário econômico desfavorável e o impeachment do Presidente Collor. Carinhato (2008) descreve o momento que o Brasil passava, no início da década de 1990, como a sintetização de desafios e contradiçôes centrados em um regime de altíssima inflação e incertezas quanto à conduçáo política que seria tomada para uma nova tentativa de arrefecimento desse fenômeno econômico. Durante o mandato do Presidente Fernando Henrique Cardoso, eleito com forte discurso de viés neoliberal, de redução da máquina estatal e de reforma do Estado, foi emitido o Decreto $\mathrm{n}^{\circ}$ 2.271, de 7 de julho de 1997, que dispôs sobre a contratação de serviços pela Administração Pública Federal direta, autárquica e fundacional, se possibilitou que as chamadas atividades materiais acessórias, instrumentais ou complementares aos assuntos que constituem a área de competência legal do órgão ou entidade (as chamadas "atividades-meio") fossem objeto de execução indireta. O mesmo texto normativo trazia ainda as atividades de conservação, limpeza, segurança, vigilância, transportes, informática, copeiragem, recepção, reprografia, telecomunicações e manutenção de prédios, equipamentos e instalações como atividades a serem preferencialmente exercidas por meio de terceirização.

Não tardou a serem extintos diversos cargos na esfera pública federal, em específico aqueles definidos como os de "nível C", cuja escolaridade mínima para o cargo era o ensino fundamental 
completo. A Lei no 9.632/1998, que dispôs sobre a extinção de cargos na Administração Pública Federal, extinguiu os cargos de apoio operacional, como auxiliar de serviços gerais, eletricista, pedreiro, encanador, marceneiro, pintor, serralheiro, entre outros. A esses cargos eram atribuídas as funçôes, em nível federal, de asseio, conservação, limpeza, vigilância, ou seja, aquelas mesmas que constavam no Decreto no 2.271 . O resultado foi a impossibilidade de realizaçáo de novos concursos públicos para provimento destes cargos, não restando alternativa senão a contratação de empresa privada "especializada", terceirizando a atividade para a devida continuidade desses serviços. Com a eventual vacância de cargos anteriormente providos por concurso e extintos pelas medidas supracitadas, ocasionados por diversos fatores como aposentadoria, exoneração, demissão ou óbito dos servidores públicos que ocupavam essas funções, restou como alterativa às instituiçôes públicas unicamente a possibilidade de fazer uso da terceirização no intuito de garantir a manutenção de seus serviços relativos às funçôes de motorista, de limpeza, de jardinagem, de copa e de recepção, de portaria e de vigilância, por exemplo.

No contexto da aprovação da Lei no 13.429, de 31 de março de 2017 - a chamada "Lei da Terceirização" - foram ampliadas as possibilidades legais de terceirização até mesmo às atividades-fim. O Decreto no 2.271 foi revogado, entrando em vigência o Decreto no 9.507, de 21 de setembro de 2018, que dispôs sobre a execução indireta, mediante contratação de serviços, de atividades pela administração pública federal direta, autárquica e fundacional, bem como pelas empresas públicas e pelas sociedades de economia mista controladas pela Uniáo. O texto normativo em questão amplia as funçóes que podem ser objeto de terceirização, incluindo as atividades-fim. Cabe destacar, ainda, que a discussão sobre a inconstitucionalidade da utilização da terceirização pela Administração Pública ainda não é tema pacificado nas áreas do Direito Constitucional, do Direito Administrativo e do Direito do Trabalho. De modo geral, neste contexto, Antunes (2000, p. 38) categoricamente coloca que:

É preciso que se diga de forma clara: desregulamentação, flexibilização, terceirização, bem como todo esse receituário que se esparrama pelo "mundo empresarial”, são expressóes de uma lógica societal onde o capital vale e a força humana de trabalho só conta enquanto parcela imprescindível para a reprodução deste mesmo capital. Isso porque o capital é incapaz de realizar sua autovalorização sem utilizar-se do trabalho humano. Pode diminuir o trabalho vivo, mas não eliminá-lo. Pode precarizá-lo e desempregar parcelas imensas, mas não pode extinguí-lo.

Por todo o exposto, temos que a terceirização nasceu no bojo de crises do capital que buscava reestruturar seu modo de produção, flexibilizando as relaçôes de trabalho num cenário de ideias e políticas públicas do neoliberalismo. Portanto, a relação entre terceirização e neoliberalismos é umbilical.

\section{A TERCEIRIZAÇÃO NA UNIVERSIDADE FEDERAL DA GRANDE DOURADOS}

À priori, cabe aqui destacar que a Fundação Universidade Federal da Grande Dourados (UFGD) foi instituída pelo desmembramento da Fundação Universidade Federal do Mato Grosso do Sul (UFMS) e pela emancipação do Centro Universitário de Dourados da Universidade Federal do Mato Grosso do Sul (CEUD-UFMS), através da Lei no 11.153, de 29 de julho de 2005. Desde 
então, a UFGD tem se consolidado enquanto instituição de ensino superior na região. Sua expansão é intrinsecamente ligada à sua inclusão no Programa de Reestruturação e Expansão das Universidades Federais (REUNI), no ano de 2007. Com o REUNI, foi possível a ampliação da oferta de vagas, criação de novos cursos e aumento do número de servidores docentes e técnicos administrativos. Como resultado desse crescimento, houve ainda o aumento das demandas das atividades de asseio e conservaçáo da infraestrutura, de modo que se permita que o público possa utilizar as dependências institucionais de forma efetiva e segura para que desenvolvam as atividades de ensino, pesquisa, extensão e administrativas.

Enquanto pessoa de direito público e como parte da Administração Pública indireta, a UFGD está sob o crivo do Decreto no 9.507/2018, sendo, portanto, obrigada a terceirizar os serviços que fujam de seu objeto finalístico desde a sua criação. Os contratos de prestação de serviços terceirizados com regime de dedicação exclusiva de mão de obra na UFGD são referentes à prestação dos serviços de limpeza e conservação; jardinagem e roçada; copa e recepção; vigilância patrimonial; portaria; motoristas; manutenção elétrica; manutenção predial (RUSSO, 2019). ${ }^{3}$ Tais atividades estão, conforme o organograma do órgão, sob o planejamento, a fiscalização e a gestão da Prefeitura Universitária (PU-UFGD). Havia, ainda,na instituição, a execução dos serviços terceirizados com regime de dedicação exclusiva de mão de obra sob a responsabilidade da Divisão de Eventos (especialistas em equipamentos de sonorização) e trabalhadores do campo (trabalhadores de apoio rural) na Fazenda Experimental de Ciências Agrárias (FAECA-UFGD) que não estão sob a responsabilidade da PU-UFGD, mas que também são executadas por trabalhadores terceirizados.

Russo (2019) descreve o patamar que se encontrava a terceirização na instituição de ensino superior, observada no primeiro momento deste artigo. Essa marcha acompanha a tendência mundial da mercantilizaçáo e privatização do ensino superior, de acordo com o autor, em um contexto mundial de crises nas instituiçóes de ensino superior e no cenário de reestruturação produtiva do capital através da implementação de políticas neoliberais. O reflexo se traduz em negação e perda de direitos laborais (como férias, benefícios do Instituto Nacional de Seguro Social/INSS e do Fundo de Garantia do Tempo de Serviço/FGTS e etc.), fragmentação da classe trabalhadora, degradação do trabalho nas universidades, desvalorização, desrespeito, invisibilidade e exclusão do trabalhador terceirizado da comunidade acadêmica. Há disparidade entre o relatório da UFGD e a pesquisa de Russo (2019): enquanto o estudo apontou cerca de 239 trabalhadores exercendo suas funçóes no campus II, em atividades de apoio da Prefeitura Universitária, no Relatório de Gestão 2018 da UFGD mais de trezentos "colaboradores" terceirizados trabalham em todos os campi.

Para desempenhar suas atividades adequadamente, a UFGD necessita contratar empresas prestadoras dos serviços de vigilância, higienização e limpeza, portaria, copeiragem, motorista, auxiliar rural entre outros, o que leva a instituiçáo a ter um total de mais de trezentos colaboradores terceirizados (UFGD, 2019, p. 24, grifo nosso).

Apesar de serem "mais de trezentos colaboradores terceirizados”, não há, nas bases normativas da instituição, menção a tal grupo. No artigo 58 de seu Estatuto, a UFGD estabelece, em rol taxativo, a composição da Comunidade Universitária: docentes, discentes e servidores técnico-administrativos:

3 Essas conclusôes constam na pesquisa de mestrado intitulada Processo de Terceirização na Universidade Federal da Grande Dourados Unidade II: Um Estudo de Caso, concluída em Maio de 2019, de Joáo Gustavo Jara Russo realizada âmbito no Programa de Pós-Graduaçáo em Sociologia. 
"Art. 58. A Comunidade Universitária será constituída pelos professores, estudantes e servidores técnico-administrativos, diversificados em suas atribuições e unificados em seus objetivos" (UFGD, 2012, p. 18). No mesmo sentido, o Regimento Geral da UFGD, enumera exaustivamentenos três capítulos do Título XI, "Da Comunidade Acadêmica": (I) Corpo Docente; (II) Corpo Técnicoadministrativo; (III) Corpo Discente. O trabalhador terceirizado, embora presente em todos os meios da instituição, não faz parte de sua comunidade acadêmica regimentalmente definida: é invisibilizado. A terceirização é, de modo geral, sinônimo de precarização do trabalho. Ainda que a Academia se proponha como ambiente plural e democrático, apenas parte dos que a frequentam usufruem de suas benesses, quais sejam, alunos, técnicos e professores. $\mathrm{O}$ quadro de empregados terceirizados está à margem do que formalmente se estabelece no regimento da instituição como sendo a comunidade acadêmica:

A defesa da terceirização pelas empresas e a ofensiva do empresariadobrasileiro pela sua desregulamentação sustentam-se no discurso da modernizaçáo organizacional, da especialização e focalização, e da criação de empregos, negando que ela traz precarizaçáo e, quando admitida, é justificada pelas "más empresas" ou "maus empresários", não se configurando como regra geral. Trata-se de um discurso que não se sustenta diante das evidências e das realidadesdo trabalho terceirizado pesquisadas (DRUCK; FILGUEIRAS, 2014, p. 110).

Nota-se que a terceirizaçáo, diferentemente do discurso defendido pelo empresariado (forma de modernização organizacional, especialização e fonte de empregos), não prospera. Pelo contrário, não há a mínima estabilidade no emprego para o terceirizado que tem, constantemente, seus direitos básicos negados e depredados, seja pela empresa prestadora de serviço, seja pelo que se dispóe em lei específica sobre a temática:

Nos anos 2000, mesmo com a mudança da conjuntura econômica internacional e a retomada do crescimento, em uma conjuntura favorável às empresas de todos os setores, a terceirização continua crescendo, atingindo também o setor público, numa clara demonstração de que não se trata de uma estratégia empresarial de resposta a uma conjuntura de crise (DRUCK; FILGUEIRAS, 2014, p. 109).

A precarização a que o trabalhador terceirizado é acometido é um tema fulcral para a sociologia do trabalho. Conforme nos ensina Antunes (2018, p. 157),

Em todas as dimensóes e modalidades de precarização do trabalho no Brasil, conforme classificação de Franco e Druck, a terceirização está presente como fenômeno central. Assim, quando se examina a dimensão 'mercado de trabalho', isto é, as formas de mercantilização da força de trabalho, encontra-se uma condição de heterogeneidade e segmentação, marcada por uma vulnerabilidade estrutural que se reconfigura, com formas de inserção (contratos) precárias, sem proteção social, com salários mais baixos, presentes na terceirização de forma exemplar e cujo crescimento exponencial pode ser observado em diferentes segmentos da classe trabalhadora.

Ademais, o autor destaca que os trabalhadores terceirizados percebem remuneração inferior aos trabalhadores não terceirizados, possuem maior jornada de trabalho, tem maior instabilidade em relação ao vínculo de trabalho e gozam de menos direitos do que os trabalhadores que possuem a 
relação clássica e bilateral de contratação, sendo os que mais morrem e se acidentam na execução de suas atividades laborais. Essas vulnerabilidades sáo fruto justamente dessa condiçáo mais precária de trabalho (ANTUNES, 2018).

Neste contexto, a UFGD, enquanto instituição federal de ensino superior criada com o intuito de promover democraticamente a educação e os princípios de cidadania, ao utilizar mão de obra terceirizada, reproduz, institucional e paradoxalmente, a lógica do capital de cortar custos financeiros às custas do trabalhador, trabalhador este que também é um cidadão e contribuinte brasileiro.

A disseminação da terceirização, nos moldes relatados, se mostra uma verdadeira epidemia no mundo do trabalho, com seu crescimento descontrolado tanto nos setores públicos quanto privados. Druck e Filgueiras (2014) em artigo chamado corroboram com este entendimento no livro Riqueza e Miséria do Trabalho no Brasil III. Crescendo de modo descontrolado, a terceirização tem se alastrado pelo mundo do trabalho de modo epidêmico, em concomitância com a pandemia do Sars-coV-2. Os trabalhadores terceirizados enfrentam em dose dupla as epidemias que dificultam ainda mais sua vida. Percebe-se que uma epidemia (a da terceirização), de cunho laboral, afeta os trabalhadores no sentido de precarização do trabalho e a pandemia do novo coronavírus os prejudica ainda mais, em uma condição constante de precarizaçáo sanitária. Com efeito, o trabalhador terceirizado é um dos que mais sofrem em decorrência da pandemia sanitária do Sars-coV-2, conforme nos diz Druck em entrevista para a EPSJC/Fiocruz (2020, online):

Embora não se tenha estatísticas oficiais sobre terceirizados no país, pesquisas mostram que eles estão em sua imensa maioria na área de serviços. E, portanto, fazem parte dos setores mais atingidos pela pandemia. Inúmeros estudos qualitativos indicam que, diante de qualquer crise econômica, os primeiros a serem penalizados são os mais vulneráveis e, dentre esses, estão os terceirizados. No caso dos serviços públicos, por exemplo, cada corte de recursos do governo implica a redução das despesas de custeio, o que tem levado à demissão de terceirizados.

A pandemia trouxe complicaçôes e desrespeito ainda maiores que reforçam a precarização do trabalho já existente no Brasil. Na UFGD, tem-se uma realidade que não é diferente. Em especial, ao desrespeito às normas de saúde no trabalho e de biossegurança, peculiares da pandemia do SarscoV-2. Evidencia Druck (2020, online), em entrevista para a Escola Politécnica de Saúde Joaquim Venâncio/Fiocruz, publicada no sítio eletrônico Outras Palavras:

Entre os trabalhadores que permaneceram trabalhando em atividades consideradas essenciais na pandemia, uma grande parte é de terceirizados. São enfermeiros, técnicos em enfermagem e médicos nos hospitais e UPAs [Unidades de Pronto Atendimento]; nos serviços de limpeza, recepçáo e segurança nas universidades, escolas, bancos, hospitais e outros. Uma gama de serviços que não pode parar, cujos trabalhadores estão expostos à contaminação diariamente, sem proteçấo suficiente, já que muitas das empresas que os contratam não oferecem condiçóes seguras de trabalho. Muitos já foram contaminados, parte sobreviveu, outros morreram, ou estáo adoecidos pelas jornadas excessivas e pela tensão permanente (grifo nosso).

Há, portanto, dois fenômenos (terceirização e pandemia da corona vírus) que, em concomitância, aumentam a vulnerabilidade do terceirizado, tornando ainda mais oportuna a exploraçáo do seu trabalho pelo capital, deixando um ambiente propício para a incidência de prejuízo e corrosão da classe, resultando na famigerada precarização do trabalho. 


\section{A CONTÍNUA INVISIBILIDADE E EXCLUSÃO DO TRABALHADOR TERCEIRIZADO DA COMUNIDADE ACADÊMICA EM MEIO À PANDEMIA}

Cabe contextualizar que, em 11 de março de 2020, o diretor-geral da Organização Mundial de Saúde (OMS) Tedros Adhanom declarou que a organização elevou o estado de contaminação à pandemia de Covid-19, doença causada pelo novo coronavírus (Sars-Cov-2). O anúncio se deu em razão de haver mais de 115 países com casos declarados de infecção. O Ministro da Saúde à época, Luiz Henrique Mandetta, declarou inicialmente que tal fato não alteraria as medidas no Brasil, que realizaria o monitoramento das áreas atingidas e a adoção dos protocolos até então anunciados. Na data, já haviam 52 casos confirmados de infecção pelo Sars-Cov-2 no país. Não havia, ainda, contaminados no Mato Grosso do Sul (AGÊNCIA BRASIL, 2020). Em 12 de Março de 2020, foi instituído na UFGD o Comitê Operativo de Emergência (COE/UFGD), cujo objetivo era deliberar sobre açôes da instituição no combate à propagação da pandemia. Suas resoluçóes têm sido divulgadas à comunidade acadêmica por meio de atas de reuniôes, disponibilizadas no sítio eletrônico da instituição. Tais atas serão objeto de análise do estudo, constituindo-se documentos de fonte primária.

O bloco documental formado através de documentação oficial expedida pela própria UFGD, em seu sítio oficial, por meio das atas do Comitê Operativo de Emergência e no Boletim de Serviços demonstram a resposta institucional da UFGD frente a pandemia até o momento, recebendo enfoque no trabalhador terceirizado. Ao se enumerar o bloco dos arquivos documentais a serem estudados, mister se faz a elaboração de um inventário exaustivo, bem como uma seleção criteriosa da informação disponibilizada (CELLARD, 2008, p. 298). Para efeitos de análise, serão considerados os documentos emitidos de março de 2020, início da pandemia, até fevereiro de 2021. Foram realizadas, até a elaboração deste artigo, cinquenta e três reunióes do COE, sendo a última realizada ao $5^{\circ}$ dia de fevereiro de 2021.

Em 12 de março de 2020, a UFGD designou o Comitê Operativo de Emergência (COE/ UFGD), conforme a Portaria n. ${ }^{\circ} 190$ de 12 de março de 2020 da Reitoria/UFGD em atendimento à Portaria MEC n. 329 de 11 de março de 2020 (UFGD, 2020a). Destaca-se que o referido Comitê foi composto somente pela alta gestão da instituição, todos com cargos de livre nomeação pela reitoria, sem a participação de membros representantes das categorias sindicais administrativa, docente, discente ou dos trabalhadores terceirizados. O Comitê foi formado, então, pela Reitora Pro Tempore, Vice Reitor Pro Tempore, Pró-reitores ${ }^{4}$, Chefe de Gabinete, Prefeito Universitário, Ouvidor, Relaçôes Públicas, Assessora de Comunicação Social e Relações Públicas, Diretor Geral Pro Tempore Do Hospital Universitário, Chefe da Unidade de Suporte às Urgências (USU) e Coordenadora de Desenvolvimento e Assistência ao Servidor. Quaisquer questóes relativas aos trabalhadores terceirizados caberiam, neste comitê, à princípio, somente à "representaçáo" dada pelo Prefeito Universitário.

A primeira reunião do COE/UFGD se deu em 13 de março de 2020, sendo deliberada a suspensão de viagens de servidores e discentes, de eventos, reunióes e a elaboração de planos para possível trabalho à distância para os servidores, com o evidente intuito de evitar a contaminação entre trabalhadores administrativos e docentes (ATA DA PRIMEIRA REUNIÃO DO COE/UFGD, 2020b). Não há menção às atividades dos trabalhadores terceirizados. A primeira citação aos terceirizados veio somente na $3^{\text {a }}$ reuniáo do Comitê Operativo de Emergência, em 17 de março de 2020, e, após debate, deliberou ser:

4 Pró-reitora de Gestão de Pessoas (PROGESP), Pró-Reitora de Avaliação Institucional e Planejamento (PROAP), Pró-Reitora de Extensão e Cultura (PROEX), Pró-Reitoria de Assuntos Comunitários e Estudantis (PROAE), Pró-Reitora de Ensino de Pós-Graduação e Pesquisa/PROPP, Pró-Reitor de Administraçáo/PRAD, Pró-Reitora de Ensino de Graduaçáo/PROE 
desnecessária a publicação de Instrução Normativa pela PRAD a respeito dos procedimentos direcionados aos terceirizados devido as Recomendaçóes referentes ao COVID-19 sobre Contratos de prestação de serviços terceirizados, postado no Portal de Compras do Governo Federal, publicadas em 16 de março de 2020 (ATA DA TERCEIRA REUNIÁO DO COE/UFGD, 2020b).

Sublinha-se que, na mesma reunião, foi deliberada a suspensão do calendário acadêmico por 30 (trinta) dias, com possibilidade de prorrogação, com o objetivo de prevenir o contágio entre discentes e docentes. No dia 21 de março de 2020, a Prefeitura Universitária (PU), publicou no Boletim de Serviços n. 4.024, a Instrução Normativa (IN) no 1 de 20 de março de 2020 (UFGD, 2020c). $\mathrm{Na}$ referida instrução, houve a determinação de que os "colaboradores" terceirizados pertencentes ao chamado "grupo de risco" deveriam ser colocados preventivamente em quarentena domiciliar, atendendo às portarias vigentes, podendo ser convocados presencialmente para atuar em acaso de incidente ou atividade caso fosse necessário (IN no 1 , de 20/03/2020, PU/UFGD). O sítio oficial da UFGD, em 24 de março de 2020, repercutiu a referida IN no 1/2020, com ênfase na execução das atividades de limpeza, que passou a realizar a desinfecção sanitária dos ambientes possivelmente contaminados:

Um dos serviços terceirizados que tem mais visibilidade e trânsito entre a comunidade acadêmica é o de limpeza. Conforme a IN, essas atividades terão turnos flexibilizados e serão feitas em forma de plantão. A limpeza interna dos blocos será realizada em todas as salas e, posteriormente, as mesmas serão devidamente trancadas. Caso alguma atividade administrativa ou de pesquisa seja realizada em algum recinto, quem a fizer deverá comunicar aos vigilantes, para que as equipes plantonistas possam executar a limpeza nos referidos ambientes. $\mathrm{O}$ procedimento de aviso deverá ser feito mesmo que o usuário permanecer no recinto por alguns instantes, visando manter os prédios desinfetados. Já a higienização externa dos setores será realizada em escala, podendo ocorrer em dias alternados (UFGD, 2020d).

Em 25 de março de 2020, em seu sítio oficial, a UFGD apresentou um panorama com as novas rotinas na execução das atividades, pormenorizando as atividades do COE/UFGD. Dentre essas novas rotinas, foram incluídas suspensão do calendário acadêmico, realização de bancas examinadoras de qualificação e de defesa de mestrado e de doutorado por videoconferência, cancelamento e adiamento de eventos presenciais, suspensão do atendimento da Biblioteca e adoção do modelo de teletrabalho, "[...] pelo qual os servidores permanecem em suas casas e continuam cumprindo suas cargas horárias e atribuiçóes, a distância” (UFGD, 2020e, online). Mantiveram-se em atendimento presencial apenas as funçóes consideradas essenciais, como Serviço de Protocolo, Almoxarifado e Patrimônio. Atendimento ao público em geral e assistência estudantil deveriam ser feito por via remota. Foram suspensos, ainda, os serviços de Restaurante Universitário e Brinquedoteca, de cursos e eventos de extensão e cultura, de convocaçóes para concursos, vestibulares e outros processos seletivos. Foram estabelecidas novas rotinas de trabalho dos trabalhadores terceirizados, com destaque ao protocolo de contato e identificação obrigatórios com o vigilante no campus II e a desinfecção de ambientes realizada pelos trabalhadores terceirizados da limpeza. Por fim, a instituição menciona 
medidas informativas que estariam sendo repassadas aos trabalhadores terceirizados, porémsem aprofundá-las:

Todos os trabalhadores estão recebendo diariamente as orientaçôes repassadas pelas autoridades de saúde sobre como protegerem a si e a outras pessoas contra o contágio. A UFGD também está em diálogo com os representantes das empresas terceirizadas para encontrar as melhores maneiras de atenuar os efeitos da pandemia (UFGD, 2020e, online).

Cabe destacar aqui que o teletrabalho, também comumente chamado de home office, é objeto de estudos na área da sociologia do trabalho e, em específico, na forma como foi viabilizado aos servidores da instituição, apresenta aspectos a serem analisados em estudos posteriores quanto à precarização da atividade laboral, como a utilização de telefones pessoais, o aumento da jornada, o estabelecimento de metas individualizadas e até mesmo o custeio dos meios de trabalho como energia elétrica, conexão à Internet e telefone. "Cada servidor tem um plano de trabalho definido com metas individuais e deverá estar inteiramente à disposição da administração da UFGD durante todo o horário de sua jornada regular, inclusive com seus telefones pessoais em atividade" (UFGD, 2020e). Destaca-se, no entanto, que há evidente preocupação institucional quanto à questão sanitária em relação aos membros de sua comunidade acadêmica, a qual não é composta pelos trabalhadores terceirizados.

A próxima menção aos trabalhadores terceirizados se deu somente na vigésima oitava reunião do COE/UFGD, realizada em 16 de abril de 2020, sendo um dos itens de pauta a retomada do pagamento do auxílio-alimentação aos trabalhadores terceirizados da UFGD, que havia sido suspenso em atenção às Recomendaçóes no Portal de Compras do Governo Federal. Foi deliberado que:

Com a publicação de novas orientaçôes do Ministério da Economia e dada à situação atual de calamidade, que seja mantido o auxílio-alimentação durante o período de suspensão. Proposta posta em votaçáo, sendo aprovada a retomada do pagamento do auxílio-alimentação aos trabalhadores terceirizados da UFGD (ATA DA VIGÉSIMA OITAVA REUNIÃO DO COE/UFGD, 2020b, online).

No mesmo dia, foi publicada "Nota sobre a prestação de serviços terceirizados durante a pandemia de COVID-19" no sítio oficial da instituição, reiterando as medidas já anunciadas na IN $\mathrm{n}^{\circ}$ 01/2020-PU/UFGD, informando que as empresas prestadoras de serviços foram notificadas a proceder campanha interna de conscientizaçáo sobre os riscos e as medidas de prevenção ao COVID-19 e vedando "o desconto de salário referente a faltas decorrentes da situação de calamidade atual, na forma do art. $3^{\circ}$ da Lei no 13.979/2020”. A Nota salienta que:

As empresas prestadores de serviços foram notificadas a proceder campanha interna de conscientizaçáo dos riscos e das medidas de prevenção para enfrentamento da emergência de saúde pública de importância internacional decorrente do coronavírus (covid-19), observadas as informaçóes e diretrizes estabelecidas pelo Ministério da Saúde (UFGD, 2020f, online).

A nota reiterou as recomendaçóes constantes no Portal de Compras do Governo Federal, que deu discricionariedade para a manutenção do repasse do pagamento de auxílio-alimentação para 
as empresas que manifestem o interesse em manter tal benefício, o que motivou a deliberação do COE/UFGD:

Adicionalmente, tendo em vista discricionariedade recentemente conferida pelo documento Recomendaçóes COVID-19 - Contratos de prestação de serviços terceirizados, a UFGD informa que manterá o pagamento da rubrica de valealimentaçáo para a empresa que optar por manter o pagamento do benefício ao trabalhador afastado devido à COVID-19 (UFGD, 2020f, online).

A última menção aos trabalhadores terceirizados nas atas do COE/UFGD se deu na quadragésima segunda reuniáo do COE/UFGD, de 5 de junho de 2020, momento no qual foi "determinado que a equipe da Unidade de Suporte à Urgência da UFGD (USU/UFGD) providencie orientaçóes e acompanhamentos com o pessoal da Prefeitura Universitária, servidores e terceirizados que realizam trabalho presencial". Não há mençôes posteriores sobre como se deu tal orientação e acompanhamento.

\section{CONSIDERAÇÕES FINAIS}

No momento em que fechamos este artigo, a questão da pandemia no Brasil ainda está em aberto. A análise do bloco documental apresenta evidencias no sentido de que o trabalhador terceirizado está sendo reiteradamente excluído das políticas institucionais tomadas para a prevenção de infecção e de contágio pelo novo coronavírus. Ressalva-se, todavia, que o bloco documental ora disponível pode não ter analisado todos os documentos internos indisponíveis no sítio oficial do órgáo, como trocas de e-mails entre servidores ou memorandos. O COE/UFGD, órgáo excepcional criado para "gerenciar questốes inerentes a assuntos sensíveis de repercussão nacional, no âmbito da UFGD”(UFGD, 2020a), em específico, a pandemia, não possui representantes de discentes, de servidores docentes ou de servidores administrativos e tampouco possui representantes dos sindicatos dos trabalhadores terceirizados que desempenham suas funçóes na Universidade.

Apesar de afastar da execução das atividades os profissionais pertencentes aos chamados "grupos de risco", a instituição estabelece protocolos como o de acesso ao campus II, que torna obrigatório o contato com os vigilantes patrimoniais, por exemplo, deixando-os expostos à contaminação. Outro protocolo que merece destaque é o de que caso haja quaisquer atividades administrativas ou de pesquisa realizadas em algum ambiente, quem realizou esta atividade deverá comunicar aos vigilantes, expondo-os, para que a equipe de trabalhadores da limpeza possa realizar a limpeza do ambiente: "O procedimento de aviso deverá ser feito mesmo que o usuário permanecer no recinto por alguns instantes, visando manter os prédios desinfetados" (UFGD, 2020e), diz a normativa, demonstrando preocupaçôes maiores com a desinfecção do ambiente imobiliário do que do profissional terceirizado que terá contato com a área possivelmente contaminada.

Destaca-se ainda que a UFGD somente tomou determinados posicionamentos, como o afastamento da execução das atividades presenciais aqueles pertencentes aos grupos de risco ou a manutenção do repasse do auxílio-alimentação do trabalhador terceirizado para a empresa que optar por fazê-lo, após recomendaçôes de órgáos superiores, como as Recomendações do Portal de Compras Governamentais do Governo Federal ou determinaçóes do Ministério da Economia. Esse posicionamento institucional, apesar de legal, demonstra como é frágil a posição do trabalhador terceirizado em relação à instituição em que executa suas funçôes.

Com o recrudescimento da pandemia e o surgimento de novas variantes, bem como a 
intensificação das medidas de austeridade propostas pela agenda neoliberal do governo federal, o panorama que se apresenta no horizonte não é animador. A Lei do Orçamento Anual (LOA), ainda não foi aprovada até o encerramento deste artigo, e já conta três meses de atraso de seu prazo regulamentar. Considerando a tendência de cortesno orçamento tanto do Ministério da Educação quanto no orçamento da UFGD, tendência esta manifesta há anos, pode haver dificuldades para que os órgãos públicos mantenham suas despesas não-obrigatórias, dentre os quais figuram os contratos de prestação de serviços terceirizados com regime de dedicação exclusiva de mão de obra, aumentando ainda mais a precarização do trabalho e gerando mais insegurança para o trabalhador terceirizado.

\section{REFERÊNCIAS}

ANTUNES, Ricardo.Trabalho e precarização numa ordem neoliberal. In: GENTILI, Pabelo; FRIGOTTO, Gaudêncio. La Ciudadania Negada. Políticas de Exclusión em la Educación y el Trabajo. Buenos Aires: CLACSO, 2000. Disponível em: http://biblioteca.clacso.edu.ar/clacso/gt/20101010021549/3antunes.pdf. Acesso em: 17 mai. 2021. p. 35-48.

BRASIL. Presidência da República. Subchefia para Assuntos Jurídicos. Decreto no 2.271, de 7 de julho de 1997 - Dispóe sobre a contratação de serviços pela Administração Pública Federal direta, autárquica e fundacional e dá outras providências. Brasília, 7 jul 1997. Disponível em <http://www.planalto.gov.br/ ccivil_03/decreto/d2271.htm>. Acesso em: 27 jul. 2019.

. Presidência da República. Casa Civil. Subchefia para Assuntos Jurídicos. Congresso Nacional. Lei no 9.632, 7 de maio de 1998 - Dispóe sobre a extinção de cargos no âmbito da Administração Pública Federal direta, autárquica e fundacional, e dá outras providências. Brasília, 7 mai 1998. Disponível em <http://www.planalto.gov.br/ccivil_03/LEIS/L9632.htm>. Acesso em: 27 jul. 2019.

Presidência da República. Casa Civil. Subchefia para Assuntos Jurídicos. Lei no 13.429, de 31 de março de 2017. Altera dispositivos da Lei n. 6.019, de 3 de janeiro de 1974, que dispóe sobre o trabalho temporário nas empresas urbanas e dá outras providências; e dispôe sobre as relações de trabalho na empresa de prestação de serviços a terceiros. Brasília, 31 de março de 2017. Disponível em < $<$ ttp://www.planalto.gov. br/ccivil 03/ Ato2015-2018/2017/Lei/L13429.htm>. Acesso em 27 jul. 2020.

; Presidência da República. Casa Civil. Subchefia para Assuntos Jurídicos. Decreto no 9.507, de 21 de setembro de 2018. Dispóe sobre a execução indireta, mediante contratação, de serviços da administração pública federal direta, autárquica e fundacional e das empresas públicas e das sociedades de economia mista controladas pela União. Brasília, 21 de setembro de 2018. Disponível em <http://www.in.gov.br/ materia/-/asset_publisher/Kujrw0TZC2Mb/content/id/42013574/do1-2018-09-24-decreto-n-9-507-de21-de-setembro-de-2018-42013422>. Acesso em 27 jul. 2020.

CARINHATO, Pedro Henrique. Neoliberalismo, Reforma do Estado e Políticas Sociais nas Últimas décadas do Século XX no Brasil. Aurora, [s.l.], ano II, n. 3, 2008.

CELLARD, André. A análise documental. In: POUPART, Jean. A Pesquisa Qualitativa: Enfoques epistemológicos e metodológicos. Trad. Ana Cristina Nasser. Petrópolis: Editora Vozes, 2008. p. 295-316.

DRUCK, Graça; FILGUEIRAS, Vitor. A Epidemia da Terceirização e a Responsabilidade do STF. Rev. TST, Brasília, vol. 80, no 3, jul/set 2014. 
DRUCK, Graça; ANTUNES, Ricardo. A Epidemia da Terceirização. In: ANTUNES, Ricardo. Riqueza e Miséria do Trabalho no Brasil III. São Paulo: Editora Boitempo, 2014. p. 13-24.

DRUCK, Graça. Hora de examinar a fundo a terceirização. Entrevistadora: Viviane Tavares. Outras Palavras, 14 out. 2020. Disponível em <https://outraspalavras.net/outrasmidias/hora-de-examinar-a-fundo-a-terceirizacao/>. Acesso em: 29 mar. 2021.

KREIN, José Dari. Tendências recentes nas relaçóes de emprego do Brasil: 1990-2005. 2007. 329 f. Tese (Doutorado) - Universidade Estadual de Campinas, Instituto de Economia, Campinas, SP, 2007.

ORGANIZAÇÃO Mundial de Saúde declara pandemia de coronavírus. Agência Brasil, Brasília, 11 mar. 2020. Disponível em <https://agenciabrasil.ebc.com.br/geral/noticia/2020-03/organizacao-mundial-da-saude-declara-pandemia-de-coronavirus $>$. Acesso em: 28 de mar. 2021.

POLÍTICA AO QUADRADO. Cortes do P2 - - \#15 Vitor Filgueiras - “O que é liberalismo?”. Youtube, 27 de abr. de 2021. Disponível em: https://www.youtube.com/watch?v=dXaKUqxTGR8. Acesso em: 17 mai. 2021.

RUSSO, João Gustavo Jara. Processo de terceirização na Universidade Federal da Grande Dourados Unidade II: um estudo de caso. 2019. 108 f. Dissertação (Mestrado em Sociologia) Universidade Federal da Grande Dourados, Dourados, MS. 2019.

UFGD. Universidade Federal da Grande Dourados. Regimento Geral. 2007. Disponível em: https://files.ufgd.edu.br/arquivos/arquivos/78/COUNI/Regimento\%20Geral\%20da\%20 UFGD_22_1_2007-.pdf>. Acesso em: 26 mar. 2020.

Estatuto. 2012. Disponível em <http://files.ufgd.edu.br//arquivos/portal/ufgd/arquivos/ aufgd/estatuto.pdf>. Acesso em 26 mar. 2020.

Relatório de Gestáo 2018. 2019. Disponível em <https://files.ufgd.edu.br/arquivos/ arquivos/78/PRESTACAO-DE-CONTAS/Relat $\%$ C3\%B3rio $\% 20$ de $\% 20$ Gest $\%$ C3\%A3o\%20 -\%20exerc\%C3\%ADcio\%202018.pdf>. Acesso em 26 mar. 2020.

Portaria no 190 de 12 de março de 2020. 2020a. Disponível em: <https://files.ufgd. edu.br/arquivos/arquivos/78/CORONAVIRUS/Portarias\%20e\%20Instru\%C3\%A7\%C3\%B5es\%20 Normativas/Portaria\%20n.\%C2\%BA\%20190.2020\%20Comit\%C3\%AA\%20Operativo\%20 Emerg\%C3\%AAncia\%20-\%20UFGD.pdf>. Acesso em: 28 mar. 2021.

Deliberaçóes do COE/UFGD. 2020b. Disponível em: <https://portal.ufgd.edu.br/secao/ coronavirus/deliberacao-do-coe-ufgd>. Acesso em: 28 mar. 2021.

Boletim de Serviços n. 4.024. Instruçáo Normativa no 1 de 20 de março de 2020. 2020c. Disponível em: <https://files.ufgd.edu.br/arquivos/arquivos/78/CORONAVIRUS/ Portarias $\% 20 \mathrm{e} \% 20$ Instru $\%$ C3\%A7\%C3\%B5es\%20Normativas/IN\%20n\%C2\%BA\%201\%20 -\%20Prefeitura\%20Universit\%C3\%A1ria.pdf>. Acesso em: 28 mar. 2021. 
Funcionários terceirizados pela UFGD também cumprirão quarentena. 2020d. Disponível em <https://www.ufgd.edu.br/noticias/funcionarios-terceirizados-pela-ufgd-tambem-cumprirao-quarentena>. Acesso em: 28 mar. 2021.

. Na prevenção à covid-19, UFGD adota novas rotinas em todos os setores.2020e. Disponível em <https://www.ufgd.edu.br/noticias/na-prevencao-a-covid-19-ufgd-adota-novas-rotinas-em-todos-os-setores>. Acesso em: 28 mar. 2021.

Nota sobre prestaçáo de serviços terceirizados durante a pandemia de covid-19. 2020 f. Disponível em <https://portal.ufgd.edu.br/noticias/nota-sobre-prestacao-de-servicos-terceirizados-durante-a-pandemia-de-covid-19>. Acesso em: 28 mar. 2021. 